\title{
Formation of Professional Competence of Students in Engineering Education
}

\author{
Elena Lisichko, Ekaterina Postnikova, Sergei I. Tverdokhlebov \\ Department of Theoretical and Experimental Physics, National Research Tomsk Polytechnic University, TPU \\ Tomsk, Russia \\ Email: tverd@tpu.ru
}

Received 2012

\begin{abstract}
Today, employers highly appreciate in addition to knowledge and skills in the professional field new abilities such as collaboration, creative approach to solving production problems, learning throughout life, the ability to adapt to changes, and the responsibility for the completed projects. The issues of the formation of professional competence among technical specialty students during the process of studying fundamental disciplines are considered. The model and the conditions of its realization using information and communication technologies are described.
\end{abstract}

Keywords: Competencies in Engineering Education; Model of Forming Competencies; Pedagogical Conditions; Information and Communication Technologies (ICT)

\section{Introduction}

Nowadays there are new demands to engineers' education (training) process according to the modern conditions of social development, improved production technologies and globalization of economics. Narrow and professional approach to education today is not sufficient, and higher education together with training of new generation specialists for labor activity should create an educated citizen, critically thinking individual, who have adopted certain cultural standards, democratic values, ethical principles. This new personality should have an ability to appreciate the moral value of actions and choices, significance of national cultural values and intercultural dialogue. Today employers, along with professional knowledge and skills appreciate new abilities such as teamwork, creativity, an ability to anticipate events and put in a broader context, resourcefulness, an ability to learn and adapt to changes, efficiency, and accountability organization. And the fundamental basis of all important and relevant disciplines in a technical institute of higher education is physics. Teaching physics is carried out during the first two years of education in college. At present, it was revealed the need to expand the role of physics in terms of building readiness of students for professional careers. The integration success of fundamental and professional training determines the understanding of readiness for professional activities [1]. To solve the problem of formation of a technical college students' readiness for professional careers during studying fundamental disciplines there was developed a special model of teaching and were formulated conditions for its functioning.

\section{Model}

According to the proposed model, student will be prepared for future career if he can cope with the project technologies for application of fundamental knowledge in solving problems in the fields of his future professional activity. To reach such re- sult it is necessary to eliminate major shortcomings of traditional training related to the inefficiency of managing cognitive activity of students [3]. This transition is about the orientation from the average student to a particular one, when teacher receives information about the quality of learning of the material directly during the process of classes and independent work; it is also about supporting students during their cognitive activity [4]. Rectification of shortcomings will be more effective if to use interactive teaching methods which include a set of pedagogical influence instruments. For an effective functioning of the formation model of students readiness for their future careers there were identified several educational criteria. The first one concerns implementation of multilevel monitoring of the formation of a technical college students readiness for professional careers during the process of learning physics with the help of information and communication technologies. The second term is about using elements of professional work during the formation of project tasks in the process of studying physics. And the participation of physics teachers and professors of relevant disciplines in the design and analytical students' activity is also important [5]. Implementation of multilevel monitoring is carried out during lectures and practical classes accomplished in the sphere of IT technologies or with its help. Such processes are based on using experimental specialized auditorium with feedback, where control of students' cognitive activities is organized in the ACS SCA environment (automated control system of students' cognitive activity). Specialized auditorium is equipped with personal computers for students. The teacher can conduct a survey in the form of testing and receive afterwards information about the level of data mastering, the degree of students' readiness to further solving and mastering of new material in real time.

It is important to conduct the first students' lecture with psychologist for taking into account personal characteristics of students, to identify the dominant trends in their behavior, their motivation concerning professional career [2]. Psychologist 
gets all the necessary psychological characteristics of students. Psychological and pedagogical feedback in ACS SCA is based on the parameters of the model, in which there is a professionally selected and adapted set of psychological techniques. They can determine the dominant trends of behavior in student studying activities and his motivational mechanism: a value orientation, the leading manner of activity and behavior strategy in achieving goals, personal meaning, determination of technical or humanitarian types of thinking, as well as their development; emotional student response in a situation of testing his knowledge level, his competence in the studying material [6]. Thus, project teams should be formed according to psychologist's results.

To educate students of engineering specialties inside the "Power and Electrical Engineering" course in Tomsk Polytechnic University a project-oriented approach is used [7]. The project-oriented approach for teaching students of technical college implies the approach based on an independent student project work, which is focused on solving of problematic situations identified on the basis of the interconnection between basic and specialized courses. From the first year of education students are involved in solving problems with a professional directivity during learning physics. To implement this approach students solve physics problems which can occur in the future professional activity. Such tasks are coordinated with departments where students learn. When analyzing tasks students generate the ideas, which they bring to life in the performance of micro- and macro-projects.

To introduce a project-oriented approach the following steps should be implemented: gradual students training to conduct project work during learning physics, identifying personal characteristics of students, building skills to work independently as well as problem-solving skills when student is in a team. On the first propedeutic (preparatory) stage it is necessary to disclose the specifics of the project activity and its importance to professional engineers. On the second stage students learn to work individually within their project activities. Teacher should give each student an opportunity to implement himself in the process of learning physics, to comprehend its fundamental mission for further understanding of the possible future career, and to learn how to use physics knowledge in future professional activities. On the third stage students need to learn how to conduct group project work. The teacher must teach students to work in a team with a creative approach to solving of professional tasks.

The transition to an independent project-oriented activity of students should be in the system "student - teacher of physics, teachers of professional branch of science", because such coordination of students' activity organization by teachers of physics and teachers of professional disciplines facilitates the identification of the most relevant issues which will be a constituent part of the professional activities of specialist [8].

It is possible to distinguish the following competencies of students which should be formed:

- the level of theoretical material;

- the formation level of professionally-oriented design skills;

- the level of motivation to the professional activity.

\section{Implemenation of the Model}

Implementing organizational and the activity model unit of the competencies formation among students of engineering specialties include preparatory, formative and final stages. Here is an example of this unit implementation for specialty "Electrical Power Systems and Networks." Currently, one of the problems to be solved by specialists of this course is the development and effective use of methods of nondestructive control of power plants' equipment. These methods include acoustic, magnetic (electromagnetic), optical, detection of defects with penetrating substances, radiative, radio wave, thermal, and electrical methods. They are the basis for the technical inspection of devices and the detection of equipment defects. Using these methods on modern production plants helps to reduce an amount of accidents, to improve durability and efficiency of the equipment.

Awareness of these methods allows forming in students the necessary competencies they will need in their professional activities. It is carried out during their further studying in special departments. The integration of professional and fundamental knowledge is accomplished by selecting physical project tasks oriented on professional career. Selection of the tasks is carried out in accordance with the following requirements: compliance with educational standards accepted by the university, compliance with students' level of training, and connection with future professional activities.

As it was already mentioned, an important stage in physics studying is to set tasks for students tailored to their future careers. Tasks are divided into elementary components and then students are checked in the classroom with feedback to identify afterwards the problematic situations. They are often caused by the lack of interconnection between physics and problematic tasks of future students' careers. The formation of the idea of solving physics tasks can be implemented within the comprehensive project. Initially, students carry out their particular projects, and then they turn them into the complete and united one. The development, presentation and project evaluation occurs with the direct participation of physics teacher and teachers of specialized disciplines (specific departments). The implementation of the proposed procedure can be considered on the example of the problem of thermal imaging (control) in the electricity industry. It should be noted that classroom time for studying the topic "Thermal radiation", which is the basis for thermal control, it is often not enough. Therefore, student projects include an independent studying of the laws of thermal radiation as the basis for thermal imaging. After this, students learn the mechanism and principle of operation of the thermal imager.

Change in the effective surface temperature of the body corresponds to the details of the visually observed pattern, so created by thermal imager visible analogue of the thermal image in pseudocolors may have a resemblance with an observed object, which is important for an objective analysis of the threats posed by defects in different instruments, devices and equipment. Based on the analysis, students make the following calculations. For example, from the temperature of fuses, measured by the thermal imager, their factory sizes, the initial resistance and the type of material (taking into account temperature coefficients for the different temperature ranges) it is possible to calculate total and specific resistance of the fuse and the energy of thermal radiation. Further, the obtained values are compared with the parameters of the limiting material melting states, taking into account the thermal losses. For insulators the thermal conductivity can be determined and if it decreases, the possibility of leakage currents should be revealed.

Individual projects developed by students are incorporated 
into a single, integrative macro-project on thermal control in the electricity industry. Project work is completed after report on the student conferences of various levels. Team of students performing macro-project may offer fellow students to answer test items on their report (after acceptance of tests with the teacher), thereby encouraging them to participate actively in the discussion.

Working within the projects increases the level of understanding and mastering of theoretical material. Students report in the form of presentations, calculation programs, calculations and animated demonstrations shows acquired competencies and create a motivation framework for future professional activities.

Motivating students to the professional activities is assessed by the goals, which students of engineering specialties try to achieve within the projects, which methods they choose, what inspires them.

Level I (low) is characterized by few positive motives for the future professional career. Basically, it is such motives as avoiding inconvenience, discomfort or narrowly personal. Cognitive interests are amorphous, situational.

Level II (intermediate) is when there is an interest to the future professional activities, all the positive motives are related only to the productive side, are focused on the success, achievement of results, and studying process in this case serves as a means towards this end.

Level III (high) implies the formation of all components, when the motivation is clear and the directivity of cognitive motives is stable.

To assess the current level of theoretical material mastering were used the results of the exams of all studied sections of the physics course. The level of formation of professionally-oriented design skills was assessed with taking into account the abilities to analyze problem situations, to get new information for solving the problem, to choose way and methods of solving the problem and the ability to work in teams. The analysis shows a tendency of increasing the level of theoretical material mastering, the level of formation of professionally-oriented design skills, motivation level to the professional activity, when using the described scheme of training.

\section{Conclusion}

Thus, the proposed model was tested with students of specialty "Electrical Power Systems and Networks" in TPU and confirms the increased levels of interest among students of engineering specialties in acquiring new knowledge and motivation to the formation of professional competencies.

\section{REFERENCES}

Haynie W.J. Anticipation of tests and open space laboratories as learning variables in technology education. Journal of the North Carolina Council of Technology Teacher Education, vol. 1(1), 1990, pp. 2-19.

Mayer R.E. \& Moreno R. Animation as an aid to multimedia learning. Educational Psychology Review, vol. 14(1), 2002, pp. 87-99.

Zinovkina M.M. Theoretical basis of purposeful forming creative technical thinking and engineering skills of the students. Moscow, Plant-technical College, 1987. - 83 p.

Laptev V.V., Shvetsky M.V. Methodical system of fundamental training in computer science: theory and practice of multi-level teaching of university education. St. Petersburg State University, 2000, 508 p.

Verbitsky A.A., Larionov O. Humanization, expertise, context - the search base integration. Journal “Alma Mater”, vol. 5, 2006, pp. 19-25.

Dubovitskaya T.D. Diagnosis of the level of vocational student. Journal of Psychological Science and Education, vol. 2, 2004, pp. 67-71.

Lisichko E., Larionov V. The method of project-problems physics teaching in classrooms with feedback. Journal "Higher Education Today”, vol. 1, 2008, pp. 82-92.

Zimnyaya I.A. Competence Approach Is it a place in the modern approaches to education? Journal "Higher Education Today", vol. 8, 2008, pp. 20-26. 